\title{
Associations of food consumption, serum vitamins and metabolic syndrome risk with physical activity level in middle-aged adults: the National Health and Nutrition Examination Survey (NHANES) 2005-2006
}

\author{
Jihyun E Choi* and Barbara E Ainsworth \\ Exercise Science and Health Promotion, School of Nutrition and Health Promotion, Arizona State University, \\ ASU Mail Code 3020, 500 N. 3rd Street, Phoenix, AZ 85004, USA
}

Submitted 11 November 2014: Final revision received 1 November 2015: Accepted 16 December 2015: First published online 17 February 2016

\begin{abstract}
Objective: To examine the associations of food consumption, serum vitamins and metabolic syndrome risk with physical activity level in middle-aged adults.

Design: Cross-sectional.

Setting: National Health and Nutrition Examination Survey (NHANES) 2005-2006.

Subjects: Adults aged 40-70 years were divided into three groups by tertile of accelerometer-determined steps/d (in men and women, respectively): tertile 1 (sedentary), <6802, <5785; tertile 2 (intermediate), 6802-10698, 5785-9225; tertile 3 (active), $\geq 10699, \geq 9226$.

Results: The active men consumed more grain products, fruits and vegetables, whereas the active women consumed more legumes and vegetables, compared with the sedentary group. Serum vitamin concentrations were associated with daily steps in both men and women. Vitamin C, $\alpha$-carotene, trans- $\beta$-carotene, cis- $\beta$-carotene, $\beta$-cryptoxanthin, lutein +zeaxanthin, lycopene, $\gamma$-tocopherol and vitamin $\mathrm{D}$ were significantly associated with daily steps. OR $(P<0.05)$ for the sedentary group were 1.52 and 1.61 for low HDL cholesterol, 1.66 and 3.97 for hypertriacylglycerolaemia, 1.02 and 2.73 for abdominal obesity, 1.79 and 1.77 for hyperglycaemia, 1.59 and 1.60 for hypertension, and 1.85 and 2.47 for metabolic syndrome in men and women, respectively.

Conclusions: Those with the highest steps taken showed a more healthful eating profile and a better serum vitamin profile compared with less active adults. Those with the lowest steps taken had greater odds of having metabolic syndrome and its risk components. Probably, daily walking is a marker of a healthful eating profile and increasing daily walking is one of the healthful ways to decrease the metabolic syndrome and its risk components.
\end{abstract}

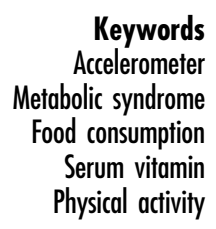

The metabolic syndrome (MetS) is a cluster of CHD risk factors: diabetes and elevated fasting blood glucose, abdominal obesity, low HDL cholesterol (HDL-C) and high blood pressure ${ }^{(1-3)}$. It is estimated that $20-25 \%$ of the world's adult population and approximately $34 \%$ of the US population have MetS ${ }^{(4)}$. Those with elevated MetS risk factors are twice as likely to die from MetS and three times as likely to have a heart attack or stroke compared with people without MetS. In addition, people with MetS have a fivefold greater risk of developing type 2 diabetes $^{(5)}$.

According to the American Heart Association ${ }^{(6)}$, the following factors have been reported as being directly associated with incident MetS in prospective or retrospective cohort studies: age, low socio-economic status, smoking, low levels of physical activity, intake of soft drinks, Western dietary pattern, heavy alcohol consumption, long-term stress at work, obesity or BMI. Four behavioural risk factors targeted in primary care to prevent and manage non-communicable diseases, including MetS and its sequelae, type 2 diabetes and CVD, are tobacco use, physical inactivity, unhealthy diet and alcohol $^{(7)}$. One of the four behavioural risk factors, physical inactivity, is not only a leading risk factor for mortality but also a significant contributor to rising health-care costs. Each year, approximately 3.2 million deaths and $32 \cdot 1$ million disability-adjusted life years, representing about $2 \cdot 1 \%$ of global disability-adjusted life years, are attributable to insufficient physical activity ${ }^{(8)}$. People who are 
insufficiently physically active have a $20-30 \%$ increased risk of all-cause mortality compared with those who engage in at least $30 \mathrm{~min}$ of moderate-intensity physical activity on most days of the week ${ }^{(9)}$. Participation in 150 min of moderate physical activity each week or equivalent is estimated to reduce the risk of IHD by approximately $30 \%$, the risk of diabetes by $27 \%$ and the risk of breast and colon cancer by $21-25 \%{ }^{(8,9)}$. In the National Health and Nutrition Examination Survey (NHANES) $2007-2008,32 \%$ of US men and 36\% of US women were obese and an additional $40 \%$ of men and $28 \%$ of women were overweight. About one in twenty Americans had a BMI of $>40 \mathrm{~kg} / \mathrm{m}^{2}$ (class III obesity) ${ }^{(10)}$. Compared with adults with a BMI of $20.0-24.9 \mathrm{~kg} / \mathrm{m}^{2}$, those with a BMI of $30 \cdot 0-34.9 \mathrm{~kg} / \mathrm{m}^{2}$ and $\geq 35 \cdot 0 \mathrm{~kg} / \mathrm{m}^{2}$ had $25 \%$ and $44 \%$ higher mean annual total (inpatient and outpatient) health-service costs, respectively ${ }^{(11)}$.

Although a large number of studies have reported associations between MetS and physical activity behaviours using questionnaires, little research has been conducted about the relationship of MetS risk with objectively measured physical activity. A literature search using the keywords 'objectively measured physical activity', 'accelerometer' and 'MetS' in PubMed yielded only fourteen articles. Studies reporting associations between daily steps and MetS yielded only two $\operatorname{articles}^{(12,13)}$. The remaining articles reported associations between intensity-related physical activity and MetS. Furthermore, to our knowledge, no studies have been published about the associations of food consumption and serum vitamins with MetS risk stratified by levels of physical activity measured by daily steps taken.

However, diet is indispensible in every day of our lives and one of the four major risk factors for non-communicable diseases $^{(7)}$. Also diet can be an immediate factor affecting the action of other factors. This means that diet is a key element in maintaining or increasing physical activity and in disease prevention or treatment. In addition, serum vitamin concentrations are closely connected with physical activity, usual food consumption and health status. For example, low levels of serum vitamins are closely associated with insufficient physical activity, insufficient consumption of fruit and vegetables, and poor health status such as overweight and MetS as well as undernutrition. In this respect, it is valuable to measure these three factors (food consumption, serum vitamin status, MetS risk) by objectively measured physical activity level. Therefore the objective of the present study was to examine the associations of food consumption, serum vitamins and MetS risk with physical activity level in middle-aged adults.

\section{Methods}

\section{Data collection}

The present study used cross-sectional data from the participants of NHANES 2005-2006. NHANES is one of a series of health-related programmes conducted by the Centers for Disease Control and Prevention's National Center for Health Statistics. The NHANES target population is the civilian, non-institutionalized US population and the survey is a stratified, multistage probability sample design. NHANES 2005-2006, one of the continuous NHANES, refers to the two-year cycles of data produced since 1999. Each cycle is divided into five sections labelled by collection method: Demographics, Dietary, Examination, Laboratory and Questionnaire. All of the NHANES fivesection data files can be linked by using the common survey participant identification number. Details of NHANES 2005-2006 can be found online ${ }^{(14)}$. We combined the five-section data to analyse associations between level of daily steps and MetS risk and to examine differences in food consumption and levels of serum vitamins by the level of daily steps. Individuals selected for the present study were adults aged 40-70 years and at high risk for MetS. NHANES 2005-2006 contains data for 10348 individuals of all ages. Among the participants, women who were pregnant or lactating and individuals whose accelerometer was not in calibration were excluded. Moreover, missing measurements that existed in Dietary, Examination and Laboratory data were removed. Therefore, the final analytical sample size (of men and women, respectively) for each analysis was as follows: (i) in sociodemographic characteristics and MetS risk analysis, $n 948$ and $n$ 982; (ii) in food group consumption analysis for $2 \mathrm{~d}$ dietary data, $n 838$ and $n$ 896; and (iii) in serum vitamins analysis, $n 747-813$ and $n 789-868$.

\section{Accelerometer-determined daily steps}

Daily steps (steps/d) were obtained from the physical activity monitor data in the NHANES 2005-2006 Examination section. The physical activity monitor component was added to NHANES in 2003, with NHANES 2005-2006 being the first release of accelerometer-determined step data along with the more commonly collected and reported intensity and duration data based on accelerometer-determined activity counts. The primary objective of the physical activity monitor component is to collect objective information on physical activity. The device used was the ActiGraph AM-7164 (formerly the CSA/MTI AM-7164), manufactured by ActiGraph LLC (Fort Walton Beach, FL, USA). This device is powered by a small watch battery with a small electric signal emitted during movement. The device is programmed to detect and record the magnitude of acceleration or intensity of movement; acceleration data are stored in memory according to a specified time interval. A 1 min time interval or 'epoch' was used to aggregate accelerometer data. As the activity monitors are not waterproof, activities such as swimming and water aerobics are not recorded. Therefore, a bias can exist because the physical activity assessment is not for a whole day if the wearer stays in a water 
environment. However, to account for day-to-day variations and reliably estimate habitual physical activity in adults, Mathews et al. suggested 3 to $5 \mathrm{~d}$ of monitoring (optimally $7 \mathrm{~d})^{(15,16)}$. In the present study, participants (948 men and 982 women) who had at least $3 \mathrm{~d}$ of accelerometer data were used in the final analysis. Additionally, 98\% of the participants had seven valid days of accelerometer data. A detailed description of the monitors and studies that have used this device is posted on the ActiGraph website ${ }^{(17,18)}$. Steps were recorded by the ActiGraph accelerometer and summed as total steps taken and steps/min for $24 \mathrm{~h}$ (1440 min).

\section{Metabolic syndrome definition}

According to the updated guideline of the US National Cholesterol Education Program Adult Treatment Panel III, MetS was defined as the presence of three or more of the following five components: (i) waist circumference (WC) $\geq 102 \mathrm{~cm}$ for men and $\geq 88 \mathrm{~cm}$ for women; (ii) $\mathrm{TAG} \geq 150$ $\mathrm{mg} / \mathrm{dl}$ or taking medication to treat hypertriacylglycerolaemia; (iii) HDL-C $<40 \mathrm{mg} / \mathrm{dl}$ for men and $<50 \mathrm{mg} / \mathrm{dl}$ for women or taking medication to treat low HDL-C; (iv) blood pressure $\geq 130 / 85 \mathrm{mmHg}$ or taking medication to treat hypertension; and (v) fasting blood glucose $\geq 100 \mathrm{mg} / \mathrm{dl}$ or taking medication to treat hyperglycaemia ${ }^{(19)}$. The MetS data were obtained from the NHANES 2005-2006 Examination, Laboratory and Questionnaire section files.

\section{Food group consumption}

In the dietary recall survey of NHANES 2005-2006, two dietary interviews were administered to all sample persons. The primary dietary interview was administered in person in the mobile examination centre (called 'the MEC in-person interview'). A follow-up dietary interview was conducted by telephone 3 to $10 \mathrm{~d}$ later from the home office (called 'the phone follow-up interview'). The two non-consecutive days of $24 \mathrm{~h}$ dietary recall do not include the same day of the week (if the in-person MEC interview was conducted on Monday, then Monday would not be an available day for scheduling a phone follow-up interview). Using a computer-assisted dietary data entry system, all foods collected from the $24 \mathrm{~h}$ dietary recall of the respondents were coded with an 8-digit, US Department of Agriculture food code. Four data files were produced from the information collected in the dietary interview by the $24 \mathrm{~h}$ dietary recall method: two Individual Foods files and two Total Nutrient Intake files. Each file includes $1 \mathrm{~d}$ of intake data. Therefore, we used the two Individual Foods files to estimate the average daily intake of each food group. We classified all foods reported in the two Individual Foods files (first day: 4052 foods; second day: 3808 foods) into nine food groups according to the US Department of Agriculture food classification: (i) milk and milk products; (ii) meat, poultry, fish and mixtures; (iii) eggs; (iv) legumes, nuts and seeds; (v) grain products; (vi) fruits; (vii) vegetables; (viii) fats, oils and salad dressings; and (ix) sugars, sweets and beverages ${ }^{(20,21)}$. Then the average consumption of these nine food groups was calculated per person per day for each group by tertile of accelerometer-determined steps/d.

\section{Serum vitamins}

Vitamin $C$, vitamin $\mathrm{B}_{12}, \alpha$-carotene, trans- $\beta$-carotene, cis- $\beta$ carotene, $\beta$-cryptoxanthin, $\gamma$-tocopherol, lutein + zeaxanthin, trans-lycopene, total lycopene, vitamin A, vitamin $\mathrm{E}$ and vitamin D in the NHANES 2005-2006 Laboratory file were used for the estimation of serum vitamin status by the level of daily steps. Detailed procedures for phlebotomy, subsequent handling of blood samples and analysis of samples, as well as reporting procedures for each of the serum vitamins, can be found online ${ }^{(14)}$. The assay methods used for measurement of serum analytes are detailed in the NHANES documentation and included the following: HPLC with electrochemical detection for vitamin C; RIA for serum vitamin $\mathrm{B}_{12}$; the two-step Diasorin procedure for vitamin $\mathrm{D}$; and HPLC with photodiode array detection for vitamins $\mathrm{A}$ and E, $\gamma$-tocopherol and the carotenoids ( $\alpha$-carotene, trans- $\beta$-carotene, cis- $\beta$-carotene, $\beta$-cryptoxanthin, lutein + zeaxanthin, trans-lycopene and total lycopene $)^{(14)}$.

\section{Statistical analysis}

Data analysis was performed separately for men and women because it is assumed that men and women have different daily steps ${ }^{(22-24)}$ and sociodemographic characteristics $^{(25,26)}$. Three categories of independent variables were created by tertile of accelerometerdetermined steps/d (in men and women, respectively): tertile 1 (sedentary), $<6802,<5785$; tertile 2 (intermediate), 6802-10698, 5785-9225; tertile 3 (active): $\geq 10699$, $\geq 9226$. Means and standard errors were calculated. In sociodemographic characteristics analysis, ANOVA with Bonferroni post hoc testing was used for multiple comparisons to determine mean differences. In food group consumption and serum vitamins analysis, univariate general linear model ANCOVA with Bonferroni post hoc testing was used. Covariates included age, BMI and total energy intake. Logistic regression was used to estimate the odds ratios and $95 \%$ confidence intervals for MetS risk. Covariates included age, BMI, total energy intake, poverty income ratio, ethnicity and education level, and the active steps/d group was considered to be a reference. All reported $P$ values are based on two-sided tests and measured to a significance level of $0 \cdot 05$. The sample weights, WTMEC2YR (full sample 2-year MEC exam weight), WTINT2YR (full sample 2-year interview weight) and WTDR2D (dietary 2-day sample weight), were used in all analyses to obtain unbiased national estimates. Statistical analyses were conducted using the Complex Samples module in the statistical software package IBM SPSS Statistics, version 19. 


\section{Results}

\section{Characteristics of the population}

Table 1 shows the sociodemographic characteristics and MetS components by physical activity group and sex. As expected, the daily steps taken were inversely associated with age in men and women. The poverty income ratio was the highest in the intermediate activity group and the lowest in the sedentary group for men and women. For ethnicity, Black men and Black women had the highest prevalence in the sedentary group while White men and Hispanic/Others women had the lowest prevalence in the sedentary group. Conversely, Black men and Black women had the lowest prevalence in the active group. For education, among men, prevalence in the sedentary group decreased with education. The highest prevalence in the active group was observed for men with 9-12 years of education. Among women, the highest prevalence in the sedentary group was observed for those with 9-12 years of education. Prevalence in the active group increased with educational attainment in women.

BMI, WC and other components of MetS such as HDL-C, TAG, fasting blood glucose and blood pressure were significantly inversely associated with daily steps. Overall, men had higher values than women for WC, and women had higher values than men for BMI, HDL-C and TAG. The increased values for the MetS components seen with lower level of daily steps were greater in women than men. Compared with other components of the MetS, TAG values decreased the greatest with higher daily steps in men and women.

\section{Food group consumption}

As shown in Table 2, compared with the sedentary group, the active men consumed significantly more grain products, fruits and vegetables, whereas the active women consumed significantly more legumes and vegetables.

\section{Serum vitamin status}

As shown in Tables 3 and 4, serum vitamin concentrations were significantly associated with daily steps in both men and women. For both sexes, the active group had the highest concentrations and the sedentary group had the lowest concentrations for vitamin $\mathrm{C}, \alpha$-carotene, trans$\beta$-carotene, $\quad$ cis- $\beta$-carotene, $\beta$-cryptoxanthin, lutein + zeaxanthin, trans-lycopene, total lycopene and vitamin D. $\gamma$-Tocopherol was the highest in the sedentary group in men and women. No differences were observed by activity group for vitamin $\mathrm{B}_{12}$, vitamin $\mathrm{A}$ and vitamin $\mathrm{E}$ among men or women.

\section{Metabolic syndrome risk}

Table 5 shows odds ratios and 95\% confidence intervals for MetS risk components. The active group was the referent group. The sedentary group had an approximate 1.9- and 2.5-fold risk for MetS in men and women, respectively. Sedentary behaviour was 1.5 to 1.8 times more likely to develop the risks for four of the five components of MetS in men and increased the risks of the five components by 1.6to 3.9-fold in women. Among participants in the sedentary group, men had the highest risks for hyperglycaemia $(\mathrm{OR}=1.79)$ and hypertriacylglycerolaemia $(\mathrm{OR}=1.66)$, and

Table 1 Sociodemographic characteristics and MetS components by tertile of daily steps in adults aged 40-70 years, NHANES 2005-2006

\begin{tabular}{|c|c|c|c|c|c|c|c|c|c|c|c|c|c|c|}
\hline \multirow[b]{3}{*}{ Characteristic } & \multicolumn{7}{|c|}{ Men } & \multicolumn{7}{|c|}{ Women } \\
\hline & \multicolumn{2}{|c|}{$\begin{array}{c}\text { Sedentary } \\
(<6802 \text { steps } / \mathrm{d} \\
n \text { 313) }\end{array}$} & \multicolumn{2}{|c|}{$\begin{array}{l}\text { Intermediate } \\
\text { (6802-10 698 } \\
\text { steps/d; } n \text { 322) }\end{array}$} & \multicolumn{2}{|c|}{$\begin{array}{c}\text { Active } \\
(\geq 10699 \text { steps } / \mathrm{d} \\
n 313)\end{array}$} & \multirow[b]{2}{*}{$P$ value ${ }^{*}$} & \multicolumn{2}{|c|}{$\begin{array}{c}\text { Sedentary } \\
(<5785 \text { steps } / \mathrm{d} ; \\
n 324)\end{array}$} & \multicolumn{2}{|c|}{$\begin{array}{c}\text { Intermediate } \\
(5785-9225 \\
\text { steps/d; } n \text { 334) }\end{array}$} & \multicolumn{2}{|c|}{$\begin{array}{c}\text { Active } \\
(\geq 9226 \text { steps } / \mathrm{d} \\
n \text { 324) }\end{array}$} & \multirow[b]{2}{*}{$P$ value ${ }^{\star}$} \\
\hline & Mean or \% & SE & Mean or \% & SE & Mean or $\%$ & SE & & Mean or \% & SE & Mean or \% & SE & Mean or \% & SE & \\
\hline Age (years) & $53 \cdot 2^{a}$ & 0.0 & $52 \cdot 5^{\mathbf{b}}$ & 0.0 & $51.9^{c}$ & 0.0 & $<0.01$ & $54 \cdot 2^{a}$ & 0.0 & $52 \cdot 2^{b}$ & 0.0 & $51 \cdot 8^{c}$ & 0.0 & $<0.01$ \\
\hline BMI $\left(\mathrm{kg} / \mathrm{m}^{2}\right)$ & $31.6^{\mathbf{a}}$ & 0.0 & $29 \cdot 1^{\mathrm{b}}$ & 0.0 & $27 \cdot 8^{c}$ & 0.0 & $<0.01$ & $32.5^{a}$ & 0.0 & $30 \cdot 4^{\mathrm{b}}$ & 0.0 & $26 \cdot 5^{c}$ & 0.0 & $<0.01$ \\
\hline WC $(\mathrm{cm})$ & $111 \cdot 3^{a}$ & 0.0 & $103.6^{b}$ & 0.0 & $100 \cdot 3^{c}$ & 0.0 & $<0.01$ & $104 \cdot 9^{a}$ & 0.0 & $98 \cdot 5^{\mathrm{b}}$ & 0.0 & $89 \cdot 2^{c}$ & 0.0 & $<0.01$ \\
\hline $\mathrm{HDL}-\mathrm{C}(\mathrm{mg} / \mathrm{dl})$ & $47 \cdot 2^{a}$ & 0.0 & $47 \cdot 3^{b}$ & 0.0 & $53 \cdot 1^{c}$ & 0.0 & $<0.01$ & $57.4^{a}$ & 0.0 & $58.8^{b}$ & 0.0 & $63 \cdot 8^{c}$ & 0.0 & $<0.01$ \\
\hline TAG (mg/dl) & $179 \cdot 5^{a}$ & 0.0 & $170 \cdot 6^{b}$ & 0.0 & $146 \cdot 3^{c}$ & 0.0 & $<0.01$ & $185 \cdot 8^{a}$ & 0.0 & $134 \cdot 4^{b}$ & 0.0 & $111.9^{c}$ & 0.0 & $<0.01$ \\
\hline FBG (mg/dl) & $115 \cdot 4^{a}$ & 0.0 & $106 \cdot 2^{b}$ & 0.0 & $104 \cdot 3^{c}$ & 0.0 & $<0.01$ & $115 \cdot 6^{a}$ & 0.0 & $102 \cdot 5^{b}$ & 0.0 & $99 \cdot 6^{c}$ & 0.0 & $<0.01$ \\
\hline $\mathrm{SBP}(\mathrm{mmHg})$ & $128 \cdot 3^{a}$ & 0.0 & $126 \cdot 9^{b}$ & 0.0 & $124 \cdot 1^{c}$ & 0.0 & $<0.01$ & $127 \cdot 8^{a}$ & 0.0 & $124 \cdot 8^{b}$ & 0.0 & $123.0^{c}$ & 0.0 & $<0.01$ \\
\hline DBP (mmHg) & $75 \cdot 3^{a}$ & 0.0 & $75 \cdot 7^{b}$ & 0.0 & $73 \cdot 6^{c}$ & 0.0 & $<0.01$ & $73.5^{a}$ & 0.0 & $72 \cdot 3^{b}$ & 0.0 & $73 \cdot 2^{c}$ & 0.0 & $<0.01$ \\
\hline PIR & $3 \cdot 2^{a}$ & 0.0 & $3 \cdot 6^{\mathrm{b}}$ & 0.0 & $3 \cdot 5^{\mathrm{c}}$ & 0.0 & $<0.01$ & $2 \cdot 9^{a}$ & 0.0 & $3 \cdot 6^{\mathrm{b}}$ & 0.0 & $3 \cdot 5^{c}$ & 0.0 & $<0.01$ \\
\hline \multicolumn{15}{|l|}{ Ethnicity (\%) } \\
\hline Hispanic/Others & $31 \cdot 1$ & & $32 \cdot 6$ & & $36 \cdot 3$ & & $<0.01$ & $22 \cdot 6$ & & $36 \cdot 3$ & & $41 \cdot 1$ & & $<0.01$ \\
\hline White & $28 \cdot 3$ & & $35 \cdot 3$ & & $36 \cdot 3$ & & & $28 \cdot 3$ & & $33 \cdot 7$ & & $38 \cdot 0$ & & \\
\hline Black & 38.2 & & 33.9 & & $27 \cdot 8$ & & & $41 \cdot 1$ & & $35 \cdot 4$ & & 23.5 & & \\
\hline \multicolumn{15}{|l|}{ Education (\%) } \\
\hline$<9$ years & $36 \cdot 3$ & & $38 \cdot 1$ & & $25 \cdot 6$ & & $<0.01$ & $27 \cdot 6$ & & $37 \cdot 5$ & & 34.9 & & $<0.01$ \\
\hline $9-12$ years & $30 \cdot 7$ & & 31.4 & & $37 \cdot 8$ & & & 33.4 & & $30 \cdot 8$ & & $35 \cdot 8$ & & \\
\hline$>12$ years & $28 \cdot 4$ & & 36.5 & & $35 \cdot 1$ & & & $26 \cdot 5$ & & $36 \cdot 1$ & & 37.4 & & \\
\hline
\end{tabular}

MetS, metabolic syndrome; NHANES, National Health and Nutrition Examination Survey; WC, waist circumference; HDL-C, HDL cholesterol; FBG, fasting blood glucose; SBP, systolic blood pressure; DBP, diastolic blood pressure; PIR, poverty income ratio.

$\mathrm{a}, \mathrm{b}, \mathrm{c}$ Mean values within a row with unlike superscript letters were significantly different (multiple comparisons between tertiles within each sex by Bonferroni post hoc test; $P<0.05)$.

${ }^{*} P$ value for difference between tertiles within each sex calculated from ANOVA. 
Table 2 Food group consumption by tertile of daily steps in adults aged 40-70 years, NHANES 2005-2006

\begin{tabular}{|c|c|c|c|c|c|c|c|c|c|c|c|c|c|c|}
\hline \multirow[b]{3}{*}{ Food group (g) } & \multicolumn{7}{|c|}{ Men } & \multicolumn{7}{|c|}{ Women } \\
\hline & \multicolumn{2}{|c|}{$\begin{array}{c}\text { Sedentary } \\
(<6802 \text { steps } / \mathrm{d} \\
n \text { 262) }\end{array}$} & \multicolumn{2}{|c|}{$\begin{array}{c}\text { Intermediate } \\
(6802-10698 \\
\text { steps/d; } n \text { 286) }\end{array}$} & \multicolumn{2}{|c|}{$\begin{array}{c}\text { Active } \\
(\geq 10699 \text { steps } / \mathrm{d} \\
n 290)\end{array}$} & \multirow[b]{2}{*}{$P$ value $^{*}$} & \multicolumn{2}{|c|}{$\begin{array}{c}\text { Sedentary } \\
(<5785 \text { steps/d; } \\
n \text { 286) }\end{array}$} & \multicolumn{2}{|c|}{$\begin{array}{c}\text { Intermediate } \\
\text { (5785-9225 } \\
\text { steps/d; } n \text { 307) }\end{array}$} & \multicolumn{2}{|c|}{$\begin{array}{c}\text { Active } \\
(\geq 9226 \text { steps } / \mathrm{d} \\
n \text { 303) }\end{array}$} & \multirow[b]{2}{*}{$P$ value ${ }^{\star}$} \\
\hline & Mean & SE & Mean & SE & Mean & SE & & Mean & SE & Mean & SE & Mean & SE & \\
\hline Milk \& milk products & 270.9 & $18 \cdot 4$ & $226 \cdot 7$ & $16 \cdot 0$ & $252 \cdot 0$ & $16 \cdot 0$ & NS & $214 \cdot 2$ & 14.5 & $202 \cdot 0$ & $13 \cdot 6$ & $235 \cdot 8$ & $13 \cdot 1$ & NS \\
\hline Meat, poultry, fish \& mixtures & 263.6 & $10 \cdot 9$ & $250 \cdot 8$ & 9.5 & $256 \cdot 4$ & 9.5 & NS & $180 \cdot 4$ & 7.5 & 179.9 & $7 \cdot 0$ & $163 \cdot 7$ & $6 \cdot 8$ & NS \\
\hline Eggs & 28.4 & 3.3 & $26 \cdot 1$ & $2 \cdot 8$ & 31.0 & $2 \cdot 8$ & NS & 21.5 & $2 \cdot 3$ & $24 \cdot 0$ & $2 \cdot 2$ & $18 \cdot 8$ & $2 \cdot 1$ & NS \\
\hline $\begin{array}{l}\text { Dry beans, peas, other } \\
\text { legumes, nuts \& seeds }\end{array}$ & 38.9 & $4 \cdot 3$ & 35.0 & 3.8 & $32 \cdot 0$ & 3.8 & NS & $19 \cdot 5^{a}$ & 3.4 & $23 \cdot 3^{a}$ & $3 \cdot 2$ & $38 \cdot 7^{\mathrm{b}}$ & $3 \cdot 1$ & $<0.01$ \\
\hline Grain products & $284 \cdot 0^{\mathrm{a}}$ & $12 \cdot 4$ & $342 \cdot 6^{\mathrm{b}}$ & $10 \cdot 8$ & $345 \cdot 5^{\mathrm{b}}$ & $10 \cdot 8$ & $<0.05$ & 243.0 & 10.4 & $265 \cdot 0$ & $9 \cdot 7$ & $267 \cdot 1$ & 9.4 & NS \\
\hline Fruits & $151 \cdot 6^{\mathrm{a}}$ & $15 \cdot 1$ & $163 \cdot 8^{a, b}$ & $13 \cdot 2$ & $202 \cdot 3^{b}$ & $13 \cdot 1$ & $<0.05$ & $145 \cdot 9$ & $11 \cdot 0$ & $153 \cdot 6$ & $10 \cdot 3$ & 174.8 & $10 \cdot 0$ & NS \\
\hline Vegetables & $174.9^{a}$ & $11 \cdot 8$ & $236 \cdot 7^{\mathrm{b}}$ & $10 \cdot 3$ & $216 \cdot 3^{b}$ & $10 \cdot 3$ & $<0.01$ & $173 \cdot 0^{\mathrm{a}}$ & $9 \cdot 2$ & $193 \cdot 1^{a, b}$ & 8.6 & $207 \cdot 8^{\mathrm{b}}$ & 8.3 & $<0.05$ \\
\hline Fats, oils \& salad dressings & 18.6 & 1.4 & $17 \cdot 2$ & $1 \cdot 2$ & $17 \cdot 3$ & $1 \cdot 2$ & NS & 14.5 & $1 \cdot 1$ & $13 \cdot 7$ & 1.0 & $15 \cdot 4$ & 1.0 & NS \\
\hline Sugar, sweets \& beverages & $2491 \cdot 1$ & $81 \cdot 6$ & 2644.5 & $71 \cdot 1$ & 2684.6 & 71.0 & NS & $2153 \cdot 7$ & $62 \cdot 1$ & 2145.5 & $58 \cdot 2$ & 2266.5 & $56 \cdot 1$ & NS \\
\hline
\end{tabular}

NHANES, National Health and Nutrition Examination Survey.

Covariates: age, BMI, total energy intake.

${ }^{\mathrm{a}, \mathrm{b}}$ Mean values within a row with unlike superscript letters were significantly different (multiple comparisons between tertiles within each sex by Bonferroni post hoc test; $P<0.05)$.

${ }^{*} P$ value for difference between tertiles within each sex calculated from general linear model ANCOVA.

women had the highest risks for hypertriacylglycerolaemia $(\mathrm{OR}=3 \cdot 97)$ and abdominal obesity $(\mathrm{OR}=2 \cdot 73)$.

\section{Discussion}

Many studies have been reported that a lack of physical activity is a major risk factor for MetS ${ }^{(27-29)}$. The present study also found that lower daily steps were significantly associated with higher risk of MetS. Compared with the active group, OR for MetS were elevated for both men (sedentary, $\mathrm{OR}=1.85$; intermediate, $\mathrm{OR}=1.29$ ) and women (sedentary, $\mathrm{OR}=2 \cdot 47$; intermediate, $\mathrm{OR}=1.55$ ). The OR for components of MetS were also significantly higher than 1.0 for sedentary and intermediate activity groups in men and women. This underscores the importance of regular physical activity in the prevention of MetS and its components in men and women. With regard to the risk difference between men and women, previous studies have reported that the association between sedentary behaviours and MetS is stronger in women than in men, and the risk of MetS is increased more in women than in men with prolonged time spent in sedentary behaviours $^{(30-32)}$. However, it is debatable whether women are more susceptible to developing MetS than men as some studies suggest that men are more likely to develop MetS than women. According to a recent study by Fernádez-Bergés et al. ${ }^{(33)}$, in persons aged up to 55 years, MetS is more frequent in men but becomes more frequent in women in persons aged over 65 years.

In addition, the present study showed that there were significant differences between men and women in the OR of the five MetS components. Men had a high risk to develop hyperglycaemia and hypertriacylglycerolaemia, while women had a high risk to develop hypertriacylglycerolaemia and abdominal obesity. In a study of
1958 older adults from the Australian Diabetes Obesity and Lifestyle Study ${ }^{(34)}$, Gardiner et al. found that overall sitting time was detrimentally associated with greater risk of having high TAG levels in both sexes, abdominal obesity in women and low HDL-C in men. Also, Travers et $a l^{(35)}$ and Williams et $a l^{(36)}$ reported that the prevalence of diabetes and elevated fasting glucose was higher in men than in women. In the present study, the OR of women for abdominal obesity was two times higher than that of men. Women's WC itself is naturally smaller than that of men, but the increase was greater in women than in men with lower daily steps (Table 1). According to a WHO report, women have a greater relative risk of CVD at lower WC than do men generally ${ }^{(37)}$. In a follow-up study of 18892 middle-aged Finnish men and women by

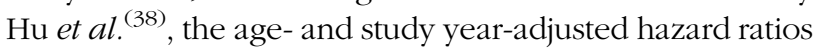
of CVD across quartiles of WC were 1.0, 1.15, 1.37 and 1.97 in men, and $1.0,1.41,1.37$ and 2.18 in women, respectively. These results and those observed in the present study indicate that while the mean of WC is smaller in women than men, the variation of WC is greater with lower daily steps and has a greater influence on the development of MetS in women than in men.

In examining the serum vitamin concentrations by daily step levels, higher concentrations of vitamin $\mathrm{C}, \alpha$-carotene, trans- $\beta$-carotene, cis- $\beta$-carotene, $\beta$-cryptoxanthin, lutein + zeaxanthin, trans-lycopene, total lycopene and vitamin D were significantly associated with higher daily steps in both sexes. These vitamins called antioxidants help protect the body against oxidative stress. The oxidative stress induced by free radicals is involved in the aetiology of a wide range of chronic diseases such as CVD, diabetes, renal disease and cancer $^{(39)}$. It has been reported that antioxidant nutrient status and exercise training have an interactive effect on oxidative stress and antioxidant enzyme activities ${ }^{(40,41)}$. This suggests that eating enough antioxidants in foods or 
Table 3 Serum vitamin concentrations by tertile of daily steps in men aged 40-70 years, NHANES 2005-2006

\begin{tabular}{|c|c|c|c|c|c|c|c|c|c|c|}
\hline \multirow[b]{2}{*}{ Serum vitamin } & \multicolumn{3}{|c|}{ Sedentary (<6802 steps/d) } & \multicolumn{3}{|c|}{ Intermediate (6802-10698 steps/d) } & \multicolumn{3}{|c|}{ Active ( $\geq 10699$ steps/d) } & \multirow[b]{2}{*}{$P$ value ${ }^{*}$} \\
\hline & $n$ & Mean & SE & $n$ & Mean & SE & $n$ & Mean & SE & \\
\hline Vitamin C (mg/dl) & 242 & $0.7^{\mathrm{a}}$ & 0.0 & 282 & $0.8^{\mathrm{a}}$ & 0.0 & 283 & $1.0^{\mathrm{b}}$ & 0.0 & $<0.01$ \\
\hline Vitamin $B_{12}(\mathrm{pg} / \mathrm{ml})$ & 239 & $494 \cdot 8$ & 54.0 & 277 & $530 \cdot 1$ & $46 \cdot 8$ & 277 & 539.6 & $46 \cdot 8$ & NS \\
\hline $\mathrm{a}-$ Carotene $(\mu \mathrm{g} / \mathrm{dl})$ & 239 & $3.3^{\mathrm{a}}$ & 0.4 & 283 & $4 \cdot 2^{a, b}$ & 0.4 & 284 & $5 \cdot 3^{\mathrm{b}}$ & 0.4 & $<0.01$ \\
\hline trans- $\beta$-Carotene $(\mu \mathrm{g} / \mathrm{dl})$ & 239 & $12 \cdot 4^{\mathrm{a}}$ & $1 \cdot 1$ & 283 & $16 \cdot 0^{\mathrm{b}}$ & 1.0 & 284 & $18 \cdot 0^{\mathrm{b}}$ & 1.0 & $<0.01$ \\
\hline cis- $\beta$-Carotene $(\mu \mathrm{g} / \mathrm{dl})$ & 223 & $0.8^{\mathrm{a}}$ & 0.1 & 267 & $1 \cdot 0^{\mathrm{a}, \mathrm{b}}$ & 0.1 & 257 & $1 \cdot 1^{\mathrm{b}}$ & 0.1 & $<0.05$ \\
\hline$\beta$-Cryptoxanthin $(\mu \mathrm{g} / \mathrm{dl})$ & 238 & $7.6^{\mathrm{a}}$ & 0.5 & 281 & $8 \cdot 6^{\mathrm{a}}$ & 0.4 & 282 & $10 \cdot 3^{\mathrm{b}}$ & 0.5 & $<0.01$ \\
\hline$\gamma$-Tocopherol $(\mu \mathrm{g} / \mathrm{dl})$ & 239 & $258 \cdot 6^{\mathrm{a}}$ & 8.6 & 282 & $232 \cdot 4^{\mathrm{a}, \mathrm{b}}$ & 7.4 & 283 & $216 \cdot 3^{\mathrm{b}}$ & $7 \cdot 3$ & $<0.01$ \\
\hline Lutein + zeaxanthin $(\mu \mathrm{g} / \mathrm{dl})$ & 239 & $14.0^{\mathrm{a}}$ & 0.7 & 283 & $16 \cdot 3^{\mathrm{b}}$ & 0.6 & 284 & $18 \cdot 9^{\mathrm{C}}$ & 0.6 & $<0.01$ \\
\hline trans-Lycopene $(\mu \mathrm{g} / \mathrm{dl})$ & 239 & $21 \cdot 5^{\mathrm{a}}$ & 0.8 & 283 & $25 \cdot 6^{\mathrm{b}}$ & 0.7 & 284 & $26 \cdot 2^{\mathrm{b}}$ & 0.7 & $<0.01$ \\
\hline Total lycopene ( $\mu \mathrm{g} / \mathrm{dl})$ & 239 & $40 \cdot 0^{\mathrm{a}}$ & 1.5 & 283 & $47 \cdot 8^{b}$ & 1.3 & 284 & $48 \cdot 9^{b}$ & 1.3 & $<0.01$ \\
\hline Vitamin $A(\mu \mathrm{g} / \mathrm{dl})$ & 239 & 66.5 & 1.2 & 283 & 65.4 & 1.0 & 284 & 65.4 & 1.0 & NS \\
\hline Vitamin E ( $\mathrm{ug} / \mathrm{dl})$ & 239 & $1269 \cdot 7$ & 32.9 & 283 & $1301 \cdot 2$ & 28.2 & 284 & 1359.5 & 28.1 & NS \\
\hline Vitamin D (ng/ml) & 245 & $22 \cdot 4^{\mathrm{a}}$ & 0.5 & 283 & $23 \cdot 1^{\mathrm{a}, \mathrm{b}}$ & 0.5 & 285 & $24 \cdot 2^{\mathrm{b}}$ & 0.5 & $<0.05$ \\
\hline
\end{tabular}

NHANES, National Health and Nutrition Examination Survey.

Covariates: age, BMI, total energy intake.

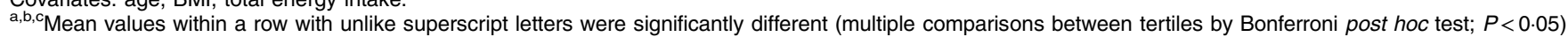

${ }^{*} P$ value for difference between tertiles calculated from general linear model ANCOVA.

Table 4 Serum vitamin concentrations by tertile of daily steps in women aged 40-70 years, NHANES 2005-2006

\begin{tabular}{|c|c|c|c|c|c|c|c|c|c|c|}
\hline \multirow[b]{2}{*}{ Serum vitamin } & \multicolumn{3}{|c|}{ Sedentary $(<5785$ steps/d) } & \multicolumn{3}{|c|}{ Intermediate (5785-9225 steps/d) } & \multicolumn{3}{|c|}{ Active ( $\geq 9226$ steps/d) } & \multirow[b]{2}{*}{$P$ value* } \\
\hline & $n$ & Mean & SE & $n$ & Mean & SE & $n$ & Mean & SE & \\
\hline Vitamin C (mg/dl) & 270 & $0.8^{\mathrm{a}}$ & 0.0 & 292 & $1 \cdot 1^{\mathrm{b}}$ & 0.0 & 296 & $1 \cdot 1^{\mathrm{b}}$ & 0.0 & $<0.01$ \\
\hline Vitamin $B_{12}(\mathrm{pg} / \mathrm{ml})$ & 263 & 527.5 & $111 \cdot 0$ & 292 & $570 \cdot 8$ & $95 \cdot 0$ & 293 & $684 \cdot 0$ & $94 \cdot 0$ & NS \\
\hline $\mathrm{a}-$ Carotene $(\mu \mathrm{g} / \mathrm{dl})$ & 272 & $4 \cdot 8^{\mathrm{a}}$ & 0.5 & 288 & $5 \cdot 6^{\mathrm{a}}$ & 0.4 & 295 & $7 \cdot 6^{\mathrm{b}}$ & 0.4 & $<0.01$ \\
\hline trans- $\beta$-Carotene $(\mu \mathrm{g} / \mathrm{dl})$ & 272 & $18 \cdot 0^{a}$ & $1 \cdot 7$ & 288 & $23 \cdot 5^{\mathrm{a}}$ & 1.5 & 295 & $30 \cdot 5^{\mathrm{b}}$ & 1.5 & $<0.01$ \\
\hline cis- $\beta$-Carotene $(\mu \mathrm{g} / \mathrm{dl})$ & 251 & $1 \cdot 1^{\mathrm{a}}$ & 0.1 & 264 & $1.4^{\mathrm{a}}$ & 0.1 & 274 & $1.9^{\mathrm{b}}$ & 0.1 & $<0.01$ \\
\hline$\beta$-Cryptoxanthin $(\mu \mathrm{g} / \mathrm{dl})$ & 271 & $7 \cdot 6^{\mathrm{a}}$ & 0.6 & 288 & $10 \cdot 0^{\mathrm{b}}$ & 0.5 & 292 & $11 \cdot 8^{\mathrm{C}}$ & 0.5 & $<0.01$ \\
\hline$\gamma$-Tocopherol $(\mu \mathrm{g} / \mathrm{dl})$ & 270 & $262 \cdot 3^{\mathrm{a}}$ & 9.5 & 286 & $224 \cdot 2^{\mathrm{b}}$ & 8.4 & 295 & $205 \cdot 9^{\mathrm{b}}$ & $8 \cdot 2$ & $<0.01$ \\
\hline Lutein + zeaxanthin $(\mu \mathrm{g} / \mathrm{dl})$ & 272 & $14 \cdot 8^{a}$ & 0.6 & 288 & $17 \cdot 1^{\mathrm{b}}$ & 0.5 & 295 & $18 \cdot 6^{\mathrm{b}}$ & 0.5 & $<0.01$ \\
\hline trans-Lycopene $(\mu \mathrm{g} / \mathrm{dl})$ & 272 & $21.5^{\mathrm{a}}$ & 0.7 & 288 & $24 \cdot 6^{\mathrm{b}}$ & 0.6 & 295 & $25 \cdot 1^{\mathrm{b}}$ & 0.6 & $<0.01$ \\
\hline Total lycopene $(\mu \mathrm{g} / \mathrm{dl})$ & 272 & $39 \cdot 8^{a}$ & $1 \cdot 3$ & 288 & $45 \cdot 7^{\mathrm{b}}$ & $1 \cdot 2$ & 295 & $46 \cdot 9^{b}$ & $1 \cdot 2$ & $<0.01$ \\
\hline Vitamin A $(\mu \mathrm{g} / \mathrm{dl})$ & 272 & $60 \cdot 1$ & 1.0 & 288 & 60.0 & 0.9 & 295 & 58.4 & 0.9 & NS \\
\hline Vitamin E ( $\mu \mathrm{g} / \mathrm{dl})$ & 272 & $1296 \cdot 8$ & $34 \cdot 0$ & 288 & 1424.4 & 29.9 & 295 & $1410 \cdot 3$ & 29.5 & NS \\
\hline Vitamin D (ng/ml) & 276 & $20 \cdot 2^{a}$ & 0.6 & 295 & $22 \cdot 8^{\mathrm{b}}$ & 0.5 & 297 & $25 \cdot 1^{\mathrm{c}}$ & 0.5 & $<0.01$ \\
\hline
\end{tabular}

NHANES, National Health and Nutrition Examination Survey.

Covariates: age, BMI, total energy intake.

作

${ }^{*} P$ value for difference between tertiles calculated from general linear model ANCOVA. 
Table 5 MetS risk by tertile of daily steps in adults aged 40-70 years, NHANES 2005-2006

\begin{tabular}{|c|c|c|c|c|c|c|c|c|c|c|c|c|}
\hline \multirow[b]{3}{*}{ MetS and five components } & \multicolumn{6}{|c|}{ Men } & \multicolumn{6}{|c|}{ Women } \\
\hline & \multicolumn{2}{|c|}{$\begin{array}{c}\text { Sedentary } \\
(<6802 \text { steps/d; } \\
\text { n 277) }\end{array}$} & \multicolumn{2}{|c|}{$\begin{array}{l}\text { Intermediate } \\
(6802-10698 \\
\text { steps/d; } n \text { 300) }\end{array}$} & \multicolumn{2}{|c|}{$\begin{array}{c}\text { Active } \\
(\geq 10699 \text { steps } / \mathrm{d} \\
n \text { 299) }\end{array}$} & \multicolumn{2}{|c|}{$\begin{array}{c}\text { Sedentary } \\
(<5785 \text { steps/d; } \\
\text { n 288) }\end{array}$} & \multicolumn{2}{|c|}{$\begin{array}{c}\text { Intermediate } \\
(5785-9225 \\
\text { steps/d; } n \text { 312) }\end{array}$} & \multicolumn{2}{|c|}{$\begin{array}{c}\text { Active } \\
\text { ( } \geq 9226 \text { steps } / \mathrm{d} ; \\
\text { n 303) }\end{array}$} \\
\hline & OR & $95 \% \mathrm{Cl}$ & OR & $95 \% \mathrm{Cl}$ & OR & $95 \% \mathrm{Cl}$ & OR & $95 \% \mathrm{Cl}$ & OR & $95 \% \mathrm{Cl}$ & OR & $95 \% \mathrm{Cl}$ \\
\hline MetS & 1.85 & $1.84,1.85$ & 1.29 & $1.28,1.29$ & 1.00 & Ref. & $2 \cdot 47$ & $2.47,2.48$ & 1.55 & $1.54,1.55$ & 1.00 & Ref. \\
\hline Low HDL-C & 1.52 & $1.51,1.52$ & 1.45 & $1.45,1.45$ & 1.00 & Ref. & 1.61 & $1.61,1.62$ & 1.35 & $1.35,1.36$ & 1.00 & Ref. \\
\hline Hypertriacylglycerolaemia & 1.66 & $1.66,1.67$ & 1.56 & $1.56,1.57$ & 1.00 & Ref. & 3.97 & $3.96,3.98$ & 1.68 & $1.68,1.69$ & 1.00 & Ref. \\
\hline Abdominal obesity & 1.02 & $1.01,1.02$ & 0.88 & $0.88,0.88$ & 1.00 & Ref. & 2.73 & $2 \cdot 72,2 \cdot 74$ & 1.50 & $1.50,1.51$ & 1.00 & Ref. \\
\hline Hyperglycaemia & 1.79 & $1.79,1.79$ & 1.25 & $1.24,1.25$ & 1.00 & Ref. & 1.77 & $1 \cdot 77,1.78$ & 1.50 & $1.50,1.51$ & 1.00 & Ref. \\
\hline Hypertension & 1.59 & $1.58,1.59$ & 1.24 & $1.24,1.25$ & 1.00 & Ref. & 1.60 & $1.59,1.60$ & 1.22 & $1.22,1.23$ & 1.00 & Ref. \\
\hline
\end{tabular}

MetS, metabolic syndrome; NHANES, National Health and Nutrition Examination Survey; HDL-C, HDL cholesterol; Ref., referent category.

Covariates: age, BMI, total energy intake, poverty income ratio, ethnicity, education.

moderate exercise may lead to increased blood vitamins and minerals and decreased oxidative stress, which can prevent development of oxidative stress-related diseases like obesity, MetS, type 2 diabetes and cancer. According to epidemiological studies, serum concentrations of $\beta$-carotene and vitamin $\mathrm{C}$ were lower in obese individuals in the SUpplémentation en VItamines et Minéraux AntioXydants (SU.VI.MAX) study, which was conducted in 1821 women aged 35-60 years and 1307 men aged 45-60 years ${ }^{(42)}$. Coyne et al. ${ }^{(43)}$ found that mean serum concentrations of $\alpha$-carotene, $\beta$-carotene and sum of five carotenoids ( $\alpha$-carotene, $\beta$-carotene, $\beta$-cryptoxanthin, lutein and lycopene) were significantly lower in persons with MetS than persons without MetS in a study conducted on 1523 adults aged 25 years and over. $\alpha$-Carotene, $\beta$-carotene and total carotenoids also decreased significantly with increased number of components of MetS. Alipanah et al ${ }^{(44)}$ determined that low total serum carotenoid ( $\alpha$-carotene, $\beta$-carotene, $\beta$-cryptoxanthin, lutein + zeaxanthin, lycopene) concentrations were associated with low walking speed and greater decline of walking speed during 3 years of follow-up. Cesari et al..$^{(45)}$ also determined that plasma antioxidant concentrations correlated positively with physical performance and strength in the part of the Invecchiare in Chianti (ageing in the Chianti area; InCHIANTI) study that was conducted in 986 people aged 65 years and older. Also, Shardell et al. ${ }^{(46)}$ observed a modest decrease in mortality for the second and third quartiles of lycopene intake in NHANES III. In another NHANES study, Patel et al. ${ }^{(47)}$ determined that serum translycopene was negatively associated with all-cause mortality. Specifically, higher levels of trans-lycopene were associated with a $20 \%$ decreased risk for mortality. Interestingly, in the present study, higher levels of serum vitamin $C$ and serum carotenoids ( $\alpha$-carotene, $\beta$-carotene, $\beta$-cryptoxanthin, lutein + zeaxanthin, trans-lycopene, total lycopene) were significantly associated with higher levels of walking and lower risks of MetS. Those people also consumed more foods rich in vitamin $\mathrm{C}$ and carotenoids, such as fruits and vegetables, as shown in Table 2. Namely, the results of our study are closely in agreement with the above findings.
Some studies have been conducted on the relationship among vitamin $\mathrm{D}$, physical activity and multiple pathological conditions including MetS, CVD and type 2 diabetes. Gagnon et al. ${ }^{(48)}$ found that lower serum vitamin D concentration was associated with increased MetS risk and higher WC, serum TAG, fasting blood glucose and insulin resistance. Thomas et $a l .{ }^{(49)}$ found that physical activity was positively associated with 25-hydroxyvitamin D (25(OH)D) level and optimal 25(OH)D levels $(\geq 75 \mathrm{nmol} / \mathrm{L})$ substantially lowered all-cause and CVD mortality in individuals with MetS. Also, Ardestani et al. ${ }^{(50)}$ confirmed that there was a significant interaction between 25(OH)D level and self-reported hours of moderate-to-vigorous physical activity and a direct relationship between $25(\mathrm{OH}) \mathrm{D}$ levels and $\mathrm{VO}_{2 \max }$ in men and women over a broad age range (20-73 years) and various serum 25(OH)D levels $(10-82 \mathrm{ng} / \mathrm{ml})$ regardless of seasonal variations of $25(\mathrm{OH}) \mathrm{D}$. Furthermore, higher levels of physical activity are generally associated with better serum vitamin D status, presumably because more outdoor physical activity can increase sun exposure and vitamin $\mathrm{D}$ production in the $\operatorname{skin}^{(16)}$. If the above research results are synthesized with the results observed in the present study, physical activity increases serum $25(\mathrm{OH}) \mathrm{D}$ level and increased serum $25(\mathrm{OH}) \mathrm{D}$ will lead to both increased $\mathrm{VO}_{2 \max }$ and reduced risks for MetS.

Perhaps the most interesting result from the present study is that $\gamma$-tocopherol was significantly inversely related with daily steps, unlike other serum vitamins. Significantly lower levels of $\gamma$-tocopherol in the active group were observed in both sexes. This result can be explained in two ways: physical activity and physical condition. Chorell et al. ${ }^{(51)}$ detected decreased levels of $\gamma$-tocopherol in highly fit individuals, suggesting that this result could be explained by an increased intracellular uptake and utilization of $\gamma$-tocopherol in highly fit individuals due to adaption to the oxidative stress during regular physical training. Also, Ford et $a l .{ }^{(52)}$ reported that $\gamma$-tocopherol concentration was positively associated with concentrations of glucose and glycosylated $\mathrm{Hb}$. In the 
study of Bates et al. ${ }^{(53)}$ using data from the British National Diet and Nutrition Survey, higher plasma $\gamma$-tocopherol was significantly directly correlated with indices of obesity such as body weight, BMI, WC and waist-to-hip ratio. This correlation was higher in adults aged 35 years and over than in young people, especially in women aged 65 years and over. In the analysis of a prospective, nested casecontrol study conducted by Hak et al. ${ }^{(54)}$, it was shown that men with high plasma $\gamma$-tocopherol levels were more likely to have an increased risk of non-fatal and fatal myocardial infarction. Therefore, for the present study, it is plausible that the $\gamma$-tocopherol concentration of the active group was the lowest as an adaption to oxidative stress caused by aerobic exercise such as walking and running to increase daily steps. On the other hand, a possible reason why the sedentary group had the highest concentration of $\gamma$-tocopherol may be because the sedentary group had some other high-risk condition that can lead to CVD, type 2 diabetes and MetS outcomes. However, other authors have shown that the decreased plasma status of $\gamma$-tocopherol and some carotenoids during the acute phase of myocardial infarction normalized the year after the myocardial infarction event in a case-control and follow-up study ${ }^{(55)}$. Their results are contrary to ours. We can interpret this strange result as follows. The mean values of $\gamma$-tocopherol in the cases and controls were too low. According to the geometric mean and selected percentile values of serum $\gamma$-tocopherol concentration for the total US population aged 6 years and older in NHANES $2005-2006^{(56)}$, the mean serum $\gamma$-tocopherol concentration of control subjects was only about the 5 th percentile value $^{(55)}$, whereas the mean serum $\gamma$-tocopherol concentrations in the present and aforementioned ${ }^{(51-54)}$ studies were about the 50th percentile value.

Regarding the food group consumption results, the male active group consumed significantly more grain products, fruits and vegetables and female active group consumed significantly more legumes and vegetables than comparison groups. Accordingly, a recent study of 1359 middleaged French persons in the SU.VI.MAX study showed that leisure-time physical activity such as walking and gardening was positively associated with eating healthy foods such as fruits and vegetables in both sexes ${ }^{(57)}$. In the Pelotas Birth Cohort Study designed to identify dietary patterns and relationships with sociodemographic and lifestyle factors of 4202 young Brazilian adults, those with a higher adherence to the vegetable/fruit dietary pattern had higher leisure-time physical activity ${ }^{(58)}$. Also, a crosssectional study of older adults aged 70 years and over showed that higher levels of physical activity assessed by accelerometry were significantly correlated with the ease of purchasing fresh fruits, vegetables and low-fat products ${ }^{(59)}$. Georgiou et al. ${ }^{(60)}$ identified that exercisers considered it more important to eat nutritious foods, ate more nutrient-dense low-fat foods, and more frequently met the Food Guide Pyramid-recommended grain and fruit intakes, than non-exercisers. Therefore, it appears that more active people eat more healthy foods and nutritious foods. The importance of fruit and vegetable consumption cannot be overemphasized because fruits and vegetables are an excellent source of various bioactive compounds including vitamins, minerals and antioxidants such as carotenoids, which have a cardioprotective effect. Also, higher levels of dietary fibre in fruits and vegetables may decrease the development of MetS by reducing blood cholesterol and lipid oxidation, and by modulating oxidative stress. All of these things make it clear that the avoidance of sedentary behaviours, healthy eating and good health are mutually connected.

The strength of the present study is that it is unique in identifying differences in food group consumption and serum vitamin status to analyse MetS risks by objectively measured daily steps in a representative sample of the US civilian non-institutionalized population. On the other hand, the weakness of the study is that detailed analysis about food consumption (e.g. separate sweets and beverages from the group of 'sugar, sweets and beverages') was not performed. Thus the study was unable to provide information on the detailed food intake affecting serum vitamin levels. A second limitation of the present study is that exact causality of the relationships among food intake, serum vitamin concentrations, daily steps and MetS cannot be suggested because of the cross-sectional design. However, as the primary study objective was to evaluate the association between daily steps and MetS and the risk conditions, and to find some difference in food intake and serum vitamin status by daily steps, the study was effective in providing new information regarding lifestyle behavioural risks for MetS. Most importantly, MetS is lowest and serum vitamin status is highest among those with the highest daily steps. Consequently, it appears that increasing daily walking is a helpful way to decrease MetS and its risk components.

\section{Acknowledgements}

Financial support: This research received no specific grant from any funding agency in the public, commercial or notfor-profit sectors. Conflict of interest: None. Authorship: J.E.C. contributed to the research questions, data analysis, and manuscript writing and editing. B.E.A. contributed to the research questions and manuscript writing and editing. Ethics of human subject participation: The NHANES 2005-2006 was approved by the NCHS (National Center for Health Statistics) Research Ethics Review Board (protocol \#2005-06).

\section{References}

1. Alberti KG, Zimmet P \& Shaw J; IDF Epidemiology Task Force Consensus Group (2005) The metabolic syndrome - a new worldwide definition. Lancet 366, 1059-1062. 
2. Alberti KG, Zimmet P \& Shaw J (2006) Metabolic syndrome - a new world-wide definition: a Consensus Statement from the International Diabetes Federation. Diabet Med 23, 469-480.

3. International Diabetes Federation (2006) The metabolic syndrome. Diabetes Voice 51, special issue, 1-44.

4. Ervin RB (2009) Prevalence of metabolic syndrome among adults 20 years of age and over, by sex, age, race and ethnicity, and body mass index: United States, 2003-2006. National Health Stat Rep issue 13, 1-8.

5. Stern M, Williams K, Gonzalez-Villalpando C et al. (2004) Does the metabolic syndrome improve identification of individuals at risk of type 2 diabetes and/or cardiovascular disease? Diabetes Care 27, 2676-2681.

6. Roser VL, Go AS, Lloyd-Jones DM et al. (2011) Heart disease and stroke statistics - 2011 update: a report from the American Heart Association. Circulation 123, e18-e209.

7. World Health Organization (2011) Fact sheet: Noncommunicable diseases. http://www.who.int/mediacentre/ factsheets/fs355/en/index.html (accessed October 2015).

8. World Health Organization (2009) Global health risks: mortality and burden of disease attributable to selected major risks. http://www.who.int/healthinfo/global_burden_ disease/GlobalHealthRisks_report_full.pdf (accessed October 2015).

9. World Health Organization (2010) Global recommendations on physical activity for health. http://whqlibdoc.who.int/ publications/2010/9789241599979_eng.pdf (accessed October 2015).

10. Flegal KM, Carroll MD, Ogden CL et al. (2010) Prevalence and trends in obesity among US adults, 1999-2008. JAMA 303, 235-241.

11. Quesenberry CP, Caan B \& Jacobson A (1998) Obesity, health services use, and health care costs among members of a health maintenance organization. Arch Intern Med $\mathbf{1 5 8}$, 466-472.

12. Camhi SM, Sisson SB, Johnson WD et al. (2011) Accelerometer-determined moderate intensity lifestyle activity and cardiometabolic health. Prev Med $\mathbf{5 2}$, 358-360.

13. Sisson SB, Camhi SM, Church TS et al. (2010) Accelerometer-determined steps/day and metabolic syndrome. Am J Prev Med 38, 575-582.

14. Centers for Disease Control and Prevention (2012) NHANES 2005-2006. http://wwwn.cdc.gov/nchs/nhanes/search/ nhanes05_06.aspx (accessed October 2015).

15. Matthews CE, Ainsworth BE, Thompson RW et al. (2012) Sources of variance in daily physical activity levels as measured by an accelerometer. Med Sci Sports Exerc 34, 1376-1381.

16. Willett W (2013) Nutritional Epidemiology, 3rd ed. New York: Oxford University Press.

17. ActiGraph (2016) Research database. http://www.acti graphcorp.com/resources/researchdatabase/ (accessed January 2016).

18. Centers for Disease Control and Prevention (2012) National Health and Nutrition Examination Survey. 2005-2006 data documentation, codebook, and frequencies. Physical activity monitor (PAXRAW_D). http://www.cdc.gov/nchs/ nhanes/nhanes2005-2006/PAXRAW_D.htm (accessed October 2015).

19. Grundy SM, Cleeman JI, Daniels SR et al. (2005) Diagnosis and management of the metabolic syndrome: an American Heart Association/National Heart, Lung, and Blood Institute Scientific Statement. Circulation 112, 2735-2752.

20. Centers for Disease Control and Prevention (2006) Health and Nutrition Examination Survey (NHANES) MEC in-person dietary interviewers procedures manual. http:// www.cdc.gov/nchs/data/nhanes/nhanes_05_06/dietary_ mec.pdf (accessed October 2015).
21. US Department of Agriculture, Agricultural Research Service (2012) The USDA food and nutrient database for dietary studies, 5.0 - documentation and user guide. http://www. ars.usda.gov/SP2UserFiles/Place/80400530/pdf/fndds/fndds5_ doc.pdf (accessed October 2015)

22. McCormack G, Giles-Corti B \& Milligan R (2006) Demographic and individual correlates of achieving 10,000 steps/day: use of pedometers in a population-based study. Health Promot J Austr 17, 43-47.

23. De Cocker K, Cardon G \& De Bourdeaudhuij I (2007) Pedometer-determined physical activity and its comparison with the International Physical Activity Questionnaire in a sample of Belgian adults. Res Q Exerc Sport 78, 429-437.

24. Hirvensalo M, Telama R, Schmidt MD et al. (2011) Daily steps among Finnish adults: variation by age, sex, and socioeconomic position. Scand J Public Health 39, 669-677.

25. Ng N, Kowal P, Kahn K et al. (2010) Health inequalities among older men and women in Africa and Asia: evidence from eight Health and Demographic Surveillance System sites in the INDEPTH WHO-SAGE Study. Glob Health Action 27, 96-107.

26. Gallo V, Mackenbach JP, Ezzati M et al. (2012) Social inequalities and mortality in Europe - results from a large multi-national cohort. PLoS One 7, e39013.

27. Carnethon MR, Gidding SS, Nehgme R et al. (2003) Cardiorespiratory fitness in young adulthood and the development of cardiovascular disease risk factors. JAMA 290, 3092-3100.

28. LaMonte MJ, Barlow CE, Jurca $\mathrm{R}$ et al. (2005) Cardiorespiratory fitness is inversely associated with the incidence of metabolic syndrome: a prospective study of men and women. Circulation 112, 505-512.

29. Ferreira I, Henry RM, Twisk JW et al. (2005) The metabolic syndrome, cardiopulmonary fitness, and subcutaneous trunk fat as independent determinants of arterial stiffness: the Amsterdam Growth and Health Longitudinal Study. Arch Intern Med 165, 875-882.

30. Bertrais S, Beyeme-Ondoua JP, Czernichow S et al. (2005) Sedentary behaviors, physical activity, and metabolic syndrome in middle-aged French subjects. Obes Res 13, 936-944.

31. Dunstan DW, Salmon J \& Owen N (2005) Associations of TV viewing and physical activity with the metabolic syndrome in Australian adults. Diabetologia 48, 2254-2261.

32. Ford ES, Kohl HW, Mokdad AH et al. (2005) Sedentary behavior, physical activity, and the metabolic syndrome among US adults. Obes Res 13, 608-614.

33. Fernández-Bergés D, Cabrera de León A, Sanz H et al. (2012) Metabolic syndrome in Spain: prevalence and coronary risk associated with harmonized definition and WHO proposal. DARIOS study. Rev Esp Cardiol 65 , 241-248.

34. Gardiner PA, Healy GN, Eakin EG et al. (2011) Associations between television viewing time and overall sitting time with the metabolic syndrome in older men and women: the Australian Diabetes, Obesity and Lifestyle study. I Am Geriatr Soc 59, 788-796.

35. Travers SH, Jeffers BW \& Eckel RH (2002) Insulin resistance during puberty and future fat accumulation. J Clin Endocrinol Metab 87, 3814-3818.

36. Williams JW, Zimmet PZ, Shaw JE et al. (2003) Gender differences in the prevalence of impaired fasting glycaemia and impaired glucose tolerance in Mauritius. Does sex matter? Diabet Med 20, 915-920.

37. World Health Organization (1997) Obesity, preventing and managing the global epidemic. http://whqlibdoc.who.int/ trs/WHO_TRS_894.pdf (accessed October 2015).

38. Hu G, Tuomilehto J, Silventoinen K et al. (2004) Joint effects of physical activity, body mass index, waist circumference 
and waist-to-hip ratio with the risk of cardiovascular disease among middle-aged Finnish men and women. Eur Heart J 25, 2212-2219.

39. Ames BN \& Gold LS (1991) Endogenous mutagens and the causes of aging and cancer. Mutat Res 250, 3-16.

40. Benderitter M, Hadj-Saad F, Lhuissier M et al. (1996) Effects of exhaustive exercise and vitamin $\mathrm{B}_{6}$ deficiency on free radical oxidative process in male trained rats. Free Radic Biol Med 21, 541-549.

41. Chang CK, Huang HY, Tseng HF et al. (2007) Interaction of vitamin $\mathrm{E}$ and exercise training on oxidative stress and antioxidant enzyme activities in rat skeletal muscles. J Nutr Biochem 18, 39-45.

42. Galan P, Viteri FE, Bertrais S et al. (2005) Serum concentrations of $\beta$-carotene, vitamins $\mathrm{C}$ and $\mathrm{E}$, zinc and selenium are influenced by sex, age, diet, smoking status, alcohol consumption and corpulence in a general French adult population. Eur J Clin Nutr 59, 1181-1190.

43. Coyne T, Ibiebele TI, Baade PD et al. (2009) Metabolic syndrome and serum carotenoids: findings of a crosssectional study in Queensland, Australia. Br J Nutr 102 , $1668-1677$.

44. Alipanah N, Varadhan R, Sun K et al. (2009) Low serum carotenoids are associated with a decline in walking speed in older women. J Nutr Health Aging 13, 170-175.

45. Cesari M, Pahor M, Bartali B et al. (2004) Antioxidants and physical performance in elderly persons: the Invecchiare in Chianti (InCHIANTI) study. Am J Clin Nutr 79, 289-294.

46. Shardell MD, Alley DE, Hicks GE et al. (2011) Low-serum carotenoid concentrations and carotenoid interactions predict mortality in US adults: the Third National Health and Nutrition Examination Survey. Nutr Res 31 , 178-189.

47. Patel CJ, Rehkopf DH, Leppert JT et al. (2013) Systematic evaluation of environmental and behavioural factors associated with all-cause mortality in the United States national health and nutrition examination survey. Int J Epidemiol $\mathbf{4 2}$, 1795-1810.

48. Gagnon C, Lu ZX, Magliano DJ et al. (2012) Low serum 25-hydroxyvitamin $\mathrm{D}$ is associated with increased risk of the development of the metabolic syndrome at five years: results from a national, population-based prospective study (The Australian Diabetes, Obesity and Lifestyle Study: AusDiab). J Clin Endocrinol Metab 97, 1953-1961.

49. Thomas GN, ó Hartaigh B, Bosch JA et al. (2012) Vitamin D levels predict all-cause and cardiovascular disease mortality in subjects with the metabolic syndrome: the Ludwigshafen
Risk and Cardiovascular Health (LURIC) Study. Diabetes Care 35, 1158-1164.

50. Ardestani A, Parker B, Mathur S et al. (2011) Relation of vitamin $\mathrm{D}$ level to maximal oxygen uptake in adults. $\mathrm{Am} \mathrm{J}$ Cardiol 107, 1246-1249.

51. Chorell E, Svensson MB, Moritz T et al. (2012) Physical fitness level is reflected by alterations in the human plasma metabolome. Mol Biosyst 8, 1187-1196.

52. Ford ES, Mokdad AH, Ajani UA et al. (2005) Associations between concentrations of $\alpha_{-}$and $\gamma$-tocopherol and concentrations of glucose, glycosylated haemoglobin, insulin and C-peptide among US adults. Br J Nutr 93, 249-255.

53. Bates CJ, Mishra GD \& Prentice A (2004) $\gamma$-Tocopherol as a possible marker for nutrition-related risk: results from four national diet and nutrition surveys in Britain. Br J Nutr 92, $137-150$

54. Hak AE, Stampfer MJ, Campos H et al. (2003) Plasma carotenoids and tocopherols and risk of myocardial infarction in a low-risk population of US male physicians. Circulation 108, 802-807.

55. Ruiz Rejon F, Martin-Pena G, Granado F et al. (2002) Plasma status of retinol, $\alpha$ - and $\gamma$-tocopherols, and main carotenoids to first myocardial infarction: case control and followup study. Nutrition 18, 26-3.

56. US Department of Health and Human Services, Centers for Disease Control and Prevention (2014) Second national report on biochemical indicators of diet and nutrition in the US population. http://www.cdc.gov/nutritionreport/pdf/ Nutrition_Book_complete508_final.pdf (accessed January 2016).

57. Charreire H, Kesse-Guyot E, Bertrais S et al. (2011) Associations between dietary patterns, physical activity (leisure-time and occupational) and television viewing in middle-aged French adults. Br J Nutr 105, 902-910.

58. Olinto MT, Willett WC, Gigante DP et al. (2011) Sociodemographic and lifestyle characteristics in relation to dietary patterns among young Brazilian adults. Public Health Nutr 14, 150-159.

59. Thompson JL, Bentley G, Davis M et al. (2011) Food shopping habits, physical activity and health-related indicators among adults aged $\geq 70$ years. Public Health Nutr $\mathbf{1 4}$, $1640-1649$.

60. Georgiou C, Betts N, Hoos T et al. (1996) Young adult exercisers and nonexercisers differ in food attitudes, perceived dietary changes, food choices. Int J Sport Nutr $\mathbf{6}$, 402-413. 